\title{
Breed Comparison of the Fatty Acid Composition of Muscle Phospholipids in Jersey and Limousin Cattle ${ }^{1}$
}

\author{
Aduli E. O. Malau-Aduli, Brian D. Siebert, Cynthia D. K. Bottema, \\ and Wayne S. Pitchford ${ }^{2}$
}

\begin{abstract}
Department of Animal Science, University of Adelaide, Waite Agricultural Research Institute,
\end{abstract} Glen Osmond, S. A. 5064, Australia

\begin{abstract}
We investigated the fatty acid composition of the phospholipid fraction of the shoulder muscle (triceps brachii) from J ersey and Limousin yearling steers, yearling heifers, and nonlactating cows. The aim was to study breed, sex, and age differences. Significant breed differences in some individual fatty acids were apparent between J ersey and Limousin cows. Limousin cows had more palmitate, vaccenate, arachidonate, and less gammalinolenate and eicosapentanoate than J ersey cows. Age differences were significant: proportions of palmitate, stearate, and oleate decreased and linoleate, arachidonate, and total polyunsaturates increased with age. Most of the breed $\times$ age interactions were not significant. Also, phospholipids of J ersey and Limousin cows did not differ in total saturated, monounsatu-
\end{abstract}

rated, and polyunsaturated fatty acids. Yearling data revealed significant sex differences in most of the fatty acids, including total monounsaturates and polyunsaturates. Yearling steers had more myristate, palmitoleate, stearate, and total monounsaturates and less linoleate, arachidonate, eicosapentanoate, and total polyunsaturates than heifers. Breed differences were also significant: Limousin yearlings had more dihomogamma-linolenate and erucate and less eicosapentanoate and nervonate than their Jersey counterparts. The sex $x$ breed interaction was not significant for most of the fatty acids. These results imply that breed, age, and sex are important factors that influence the fatty acid composition of muscle phospholipids in cattle.

Key Words: Breeds, Muscle, Phospholipids, Fatty Acids, Limousin, J ersey

@)1998 American Society of Animal Science All rights reserved.

J. Anim. Sci. 1998. 76:766-773

\section{Introduction}

The fatty acid composition of intramuscular fats is of major interest because 1) those from triacylglycerols can have a significant effect on human health, and 2) fatty acids of phospholipid can have a significant effect on animal metabolism and growth. Phospholipid fatty acids may well be part of the cause of differential growth between genotypes. They have been shown to play significant roles in reproductive and skeletal muscle tissues (Simopoulos, 1994), are known to affect cell and anabolic processes (Scott and Ashes, 1993), and are required for brain and retinal development and function (Van Oeckel et al., 1996).

\footnotetext{
${ }^{1}$ This study was funded by the J.S. Davies Bequest Fund to the University of Adelaide, the South Australian Cattle Compensation Trust Fund, and the Australian Development Cooperation Scholarship from AusAID for A.E.O. Malau-Aduli.

${ }^{2}$ To whom correspondence should be addressed.

Received May 27, 1997.

Accepted October 9, 1997.
}

It may be possible to modify the fatty acid composition of bovine muscle using selective breeding. However, for any selection program to be effective, the breeds must vary. There is evidence of genetic variation in the fatty acid composition of triacylglycerols in the adipose tissue of J ersey and Limousin (Malau-Aduli et al., 1997), Brahman and Hereford (Huerta-Leidenz et al., 1993), and Holstein and J apanese Black (Zembayashi et al., 1995) cattle. Published reports on breed comparisons of bovine muscle phospholipids are scarce. Possible breed differences in muscle phospholipid fatty acid composition should be evaluated, especially in purebred cattle. Therefore, we compared muscle phospholipids in purebred, pasture-fed cattle to ascertain the effects of breed, age, and sex on fatty acid composition.

\section{Materials and Methods}

Animals and Management. The animals used in this study were part of the parental generation of the J.S. Davies Cattle Gene Mapping Project Herd held at 
Table 1. Average characteristics and numbers of animals sampled $( \pm$ SE) for muscle phospholipid analysis

\begin{tabular}{lccc}
\hline \hline Animals & No. & Weight, kg & Age, mo \\
\hline Cows & & & \\
J ersey & 57 & $334 \pm 9$ & $\begin{array}{c}37 \pm 3 \\
\text { (range 20-68) } \\
43 \pm 4 \\
\text { (range 29-96) }\end{array}$ \\
$\begin{array}{l}\text { Limousin } \\
\begin{array}{l}\text { Yearling heifers } \\
\text { J ersey }\end{array}\end{array}$ & 32 & $449 \pm 11$ & $13 \pm 3$ \\
$\begin{array}{l}\text { Limousin } \\
\text { Yearling steers } \\
\text { J ersey }\end{array}$ & 10 & $190 \pm 17$ & $19 \pm 3$ \\
Limousin & 5 & $265 \pm 17$ & $13 \pm 6$ \\
& 5 & $282 \pm 28$ & $12 \pm 6$ \\
\hline
\end{tabular}

Martindale, a property located about $150 \mathrm{~km}$ north of Adelaide, South Australia. They included 119 J ersey and Limousin nonlactating, nonpregnant cows and yearling heifers and steers as shown in Table 1. Limousin cows, heifers, and steers were heavier than their J ersey counterparts. Limousin cows (43 mo) were also, on the average, older than the J ersey cows (37 mo), but the heifers and steers were yearlings. They were all fed on pasture only to eliminate dietary variation. They were all maintained in the same herd under the same routine management.

Sampling of Muscle Biopsies. The animals were gently restrained in a crush, and the hair around the shoulder muscle (triceps brachii) was clipped. A local anesthetic was injected at the sampling site before $3 \mathrm{~g}$ of muscle was taken. Antibiotics were administered to prevent secondary infection. The muscle samples were snap-frozen in liquid nitrogen, flushed with nitrogen gas, transported to the laboratory, and stored at $-20^{\circ} \mathrm{C}$ until the samples were analyzed for fatty acid composition. The incision was closed using metal staples after antiseptic cream and powder were applied as wound dressing to prevent infection. The incision site was coated with tar to prevent contact with dust and flies. After surgery, the animals were checked daily during the time the wounds healed.

Lipid Extraction. Approximately $.1 \mathrm{~g}$ of the muscle sample was frozen in liquid nitrogen, placed in a mortar, and pulverized with a pestle into finely ground powder. Total lipids were extracted using chloroform-methanol $(2: 1, \mathrm{vol} / \mathrm{vol})$ containing butylated hydroxytoluene (BHT) crystals as an antioxidant as recommended by Christie (1989).

Phospholipid Separation. The extracted lipids were separated into classes by TLC using $100 \mu \mathrm{L}$ of the lipid extract reconstituted in hexane. The extract was spotted onto silica gel G plates $(200 \times 200 \times .25 \mathrm{~mm})$ with a micropipette. The TLC plate was developed in an acetone/petroleum ether $(1: 3 \mathrm{vol} / \mathrm{vol})$ solvent system in a tank containing a few crystals of BHT to prevent oxidation. Triacylglycerols and free fatty acids migrated while phospholipids remained at the origin of the plate. The areas corresponding to the phospholipids were scraped off the plate and transferred to clean screw-capped test tubes for methylation.

Methylation. The silica gel scrapings from TLC were dissolved in $100 \mu \mathrm{L}$ of $.5 \mathrm{M}$ sodium methoxide in methanol. This was vortexed and allowed to stand for $5 \mathrm{~min}$ before adding $5 \mu \mathrm{L}$ of glacial acetic acid and $1 \mathrm{~g}$ of anhydrous calcium chloride as a drying agent. This mixture was allowed to stand for $1 \mathrm{~h}$. The drying agent was precipitated by centrifugation at $800 \times \mathrm{g}$ for $3 \mathrm{~min}$, after which the supernatant was transferred to a clean screw-capped test tube and $3 \mathrm{~mL}$ of water was added to remove the acetic acid. The mixture was vortexed and centrifuged, and the upper layer was transferred to another clean test tube. The organic extract was then dried at $40^{\circ} \mathrm{C}$ in a heating block under a thin stream of nitrogen gas. The dried fatty acid methyl esters were reconstituted in $100 \mu \mathrm{L}$ of trimethyl pentane in vials ready for chromatographic analysis.

Fatty Acid Analysis. Fatty acid concentration was determined with gas-liquid chromatography using a Hewlett Packard Model 5890A Series II gas chromatograph. The instrument was equipped with a 25-m $\times$.32-mm (i.d.) fused silica capillary column (BPX70, SGE Pty Ltd, Melbourne, Australia). Fatty acid methyl ester ( FAME) preparations were injected $(.1 \mu \mathrm{L})$ into the instrument using the cold on-column technique. The carrier gas was helium (head pressure $30 \mathrm{kPa}$ ), and the column was programmed from an initial temperature of $150^{\circ} \mathrm{C}(0 \mathrm{~min})$ to a final temperature of $210^{\circ} \mathrm{C}(5 \mathrm{~min})$ at the rate of $2^{\circ} \mathrm{C} / \mathrm{min}$. Chromatograms were recorded with a computing integrator (Hewlett Packard Model 3396 Series II). Standard FAME mixtures were used to calibrate the gas chromatograph system using reference standards GLC-68-B, Nu-Check Prep (Elysian, M N). I dentification of sample fatty acids was made by comparing the relative retention times of FAME peaks from samples with those of standards. These were calculated as normalized area percentages of fatty acid.

Statistical Analyses. All data were analyzed with least squares analysis of variance using PROC GLM Type 1 Sums of Squares (SAS, 1989). The model for the cow data included the fixed effects of breed, the partial regression on age, and the age $\times$ breed interaction (Table 2). Initial analysis included weight as a covariate, but this was dropped from the model because it was not a significant source of variation. The model used for the yearling data included the fixed effects of sex and breed, and the sex $\times$ breed interaction. The indices of $\Delta^{9}$-desaturase and el ongase enzymes were calculated using formulas described previously (Malau-Aduli et al., 1997) and described in Table 3. Least squares means and breed differences between means were computed and significance was defined as $\mathrm{P}<.05$. 
Table 2. Statistical models and factors fitted for least squares analysis

\begin{tabular}{|c|c|c|c|c|c|c|}
\hline \multirow[b]{2}{*}{ Trait $^{a}$} & \multicolumn{3}{|c|}{ Cow data } & \multicolumn{3}{|c|}{ Yearling data } \\
\hline & Breed & Age & Breed $\times$ age & Sex & Breed & Sex $\times$ breed \\
\hline $14: 0$ & NS & NS & NS & $* *$ & $* *$ & $* *$ \\
\hline 14:1 & NS & NS & NS & NS & NS & NS \\
\hline $16 \mathrm{DMA}^{\mathrm{b}}$ & NS & NS & NS & $* *$ & $*$ & NS \\
\hline 16:0 & * & $* *$ & NS & NS & NS & $* *$ \\
\hline $16: 1$ & NS & NS & NS & $* *$ & NS & NS \\
\hline 17:0 & $*$ & NS & NS & NS & NS & NS \\
\hline 17:1 & NS & NS & NS & NS & NS & NS \\
\hline 18DMA & NS & NS & NS & $* *$ & NS & NS \\
\hline 18:0 & NS & $* *$ & NS & $* *$ & $* *$ & NS \\
\hline $18: 1(n-9)$ & NS & $* *$ & NS & $* *$ & NS & NS \\
\hline 18:1(n-7) & NS & NS & NS & $* *$ & NS & NS \\
\hline 18:2 & NS & NS & NS & $* *$ & NS & NS \\
\hline 18:3(n-6) & $* *$ & $* *$ & NS & $*$ & NS & NS \\
\hline 18:3(n-3) & $* *$ & NS & NS & $* *$ & NS & NS \\
\hline $18: 4$ & $*$ & NS & NS & NS & NS & NS \\
\hline $20: 0$ & NS & $* *$ & NS & NS & NS & NS \\
\hline 20:1 & NS & $*$ & NS & NS & NS & NS \\
\hline $20: 2$ & NS & NS & NS & NS & NS & NS \\
\hline $20: 3$ & $*$ & NS & $* *$ & NS & $*$ & NS \\
\hline $20: 4$ & $* *$ & NS & NS & $* *$ & NS & NS \\
\hline $20: 5$ & $* *$ & $* *$ & NS & $* *$ & $* *$ & NS \\
\hline 22:0 & NS & $* *$ & NS & NS & NS & NS \\
\hline $22: 1$ & NS & NS & NS & $* *$ & $* *$ & $* *$ \\
\hline $22: 5$ & NS & NS & $*$ & NS & NS & NS \\
\hline $24: 0$ & $*$ & $* *$ & NS & NS & NS & NS \\
\hline $22: 6$ & NS & NS & NS & NS & NS & NS \\
\hline 24:1 & NS & $* *$ & NS & NS & NS & NS \\
\hline Total SFA & NS & NS & NS & NS & NS & $*$ \\
\hline Total MUFA & NS & NS & NS & $* *$ & NS & NS \\
\hline Total PUFA & NS & NS & $*$ & $* *$ & NS & NS \\
\hline$(n-3) P U F A$ & NS & NS & NS & $* *$ & NS & NS \\
\hline$(n-6) P U F A$ & NS & NS & NS & $* *$ & NS & NS \\
\hline \multicolumn{7}{|l|}{ Ratio of unsaturated: } \\
\hline $\begin{array}{l}\text { saturated } \\
\text { Ratio of polvunsatu- }\end{array}$ & NS & NS & NS & NS & NS & NS \\
\hline \multicolumn{7}{|l|}{ Ratio of polyunsatu- } \\
\hline$\Delta^{9}$-desat $(16)$ & $*$ & NS & NS & NS & $*$ & NS \\
\hline$\Delta^{9}$-desat(18) & NS & NS & NS & NS & $* *$ & NS \\
\hline Elongase & $*$ & NS & NS & $*$ & NS & $*$ \\
\hline
\end{tabular}

${ }^{a}$ Abbreviations of traits are explained in Table 3.

bDMA = di-methyl-acetals (Sinclair and O'Dea, 1987).

${ }^{\mathrm{C} S}=$ not statistically significant.

$* \mathrm{P}<.05$.

$* * \mathrm{P}<.01$.

\section{Results}

Cow Data. Phospholipids of Limousin cows differed in fatty acid composition from those of J ersey cows (Table 2). The percentages of 16:0 (palmitate), 18: 1 (n-7) (vaccenate), 20:3 (di-homo-gammalinolenate), and 20:4 (arachidonate) were higher in Limousin than in J ersey cows. However, Limousin had lower percentages of 17:0 (margerate), 18:3(n-6) (gamma-linolenate), 18:4(octadecatetraenoate), 20:5 (eicosapentanoate), 24:0 (Iignocerate), and indices of $\Delta^{9}$-desaturase (C16) and elongase activities than J ersey cows (Table 3). However, breed was not a significant source of variation in total saturated ( SFA), monounsaturated (MUFA), and polyunsaturated (PUFA) fatty acids. In both breeds, 18:
1 (n-9) (oleate) was the most abundant fatty acid, totaling 18.3 and $16.9 \%$ in Limousin and J ersey cows, respectively (Table 3 ).

Age was a significant source of variation in the percentages of 16:0, 18:0 (stearate), 18:1(n-9), 18: 3(n-6) (gamma-linolenate), 20:0 (arachidate), 20:1 (gondoate), 20:5, 22:0 (behenate), 24:0, and 24:1 (nervonate) (Table 2). Because palmitate, stearate, and oleate made up 46.4 and $49.8 \%$ of the total fatty acids in J ersey and Limousin cows, respectively (Table 3), a regression of these three fatty acids across the appropriate range of ages was carried out (Figures 1 to 3 ). As age increased, the percentages of 16:0, 18:0, and 18:1(n-9) decreased (Figures 1 to 3). In contrast, the percentage of total PUFA increased with age (Figure 4$)$. The $R^{2}$ values for all of the 


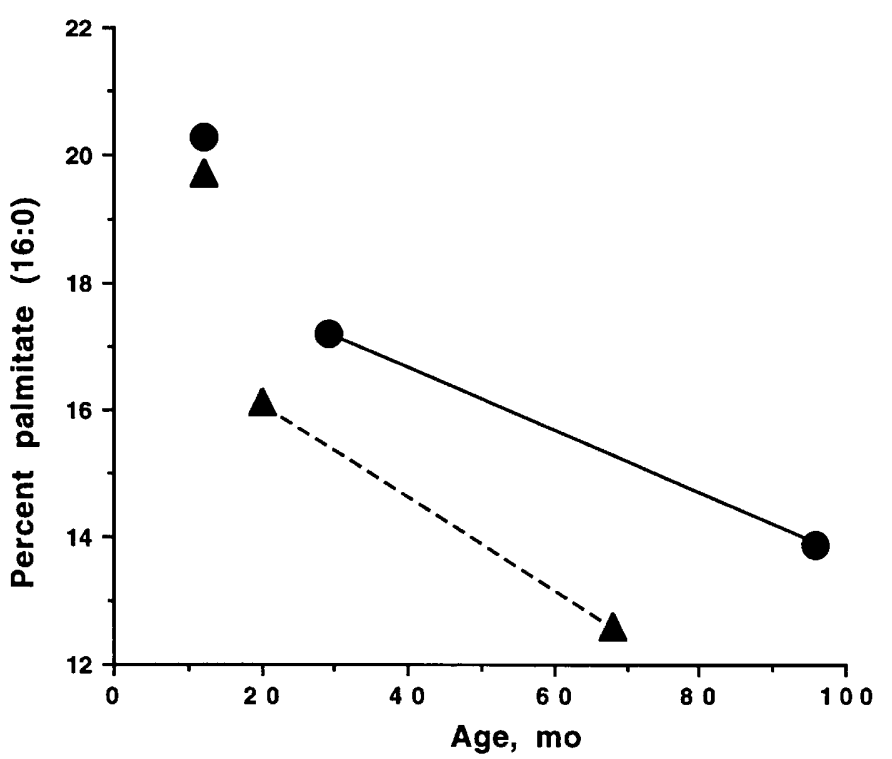

Figure 1. Relationship between muscle phospholipid palmitate and age. The unjoined data points represent yearling figures, and the joined points are calculated cow data points at the minimum and maximum age ranges. $\boldsymbol{\Lambda}=$ Jersey (palmitate $=16.9-.06$ Age) $\cdot \bullet=$ Limousin (palmitate $=18.6-.05 \mathrm{Age}$ ). $\mathrm{R}^{2}=.03$. Standard error of the difference was 1.4 for intercepts and .03 for slopes.

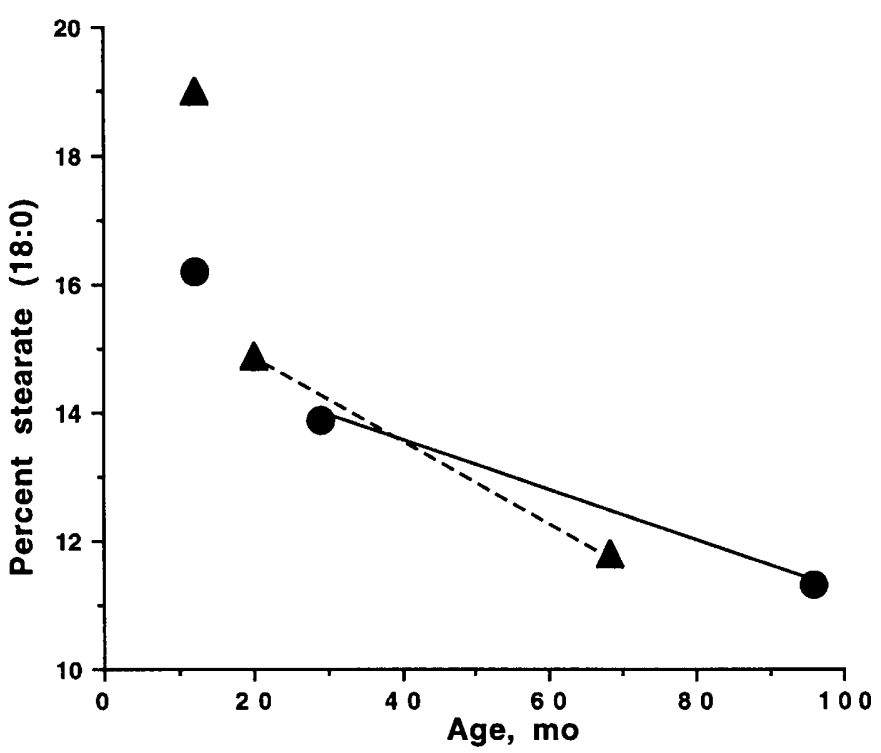

Figure 2. Relationship between muscle phospholipid stearate and age. The unjoined data points represent yearling figures, and the joined points are calculated cow data points at the minimum and maximum age ranges. $\boldsymbol{\Delta}=$ Jersey (stearate $=16.2-.07$ Age) $\cdot \bullet=$ Limousin (stearate $=15.0-.04 \mathrm{Age}$ ). $\mathrm{R}^{2}=.09$. Standard error of the difference was 1.2 for intercepts and .02 for slopes.

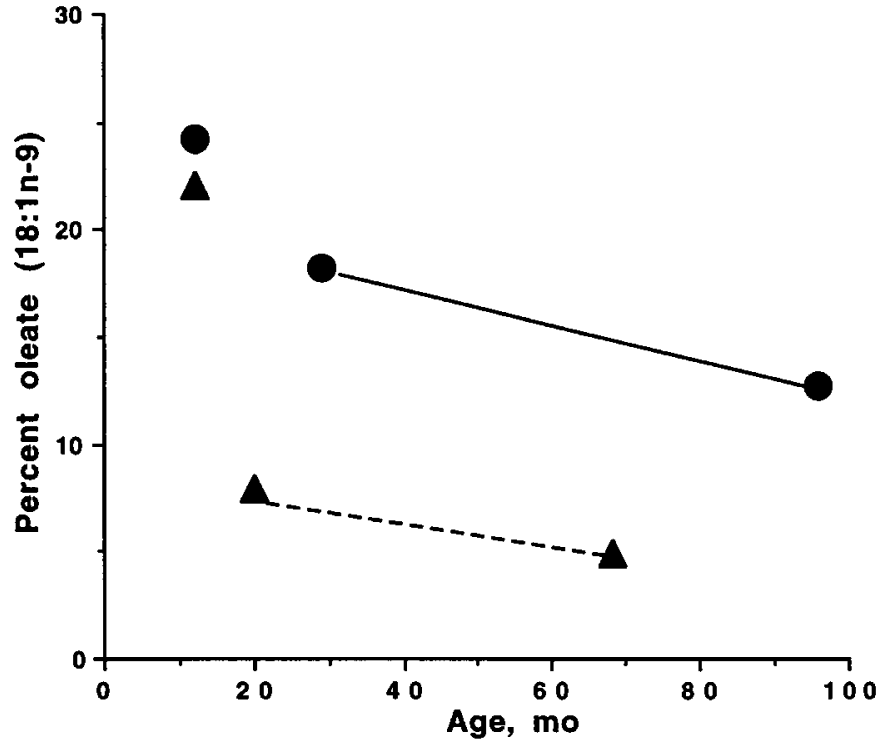

Figure 3. Relationship between muscle phospholipid oleate and age. The unjoined data points represent yearling figures, and the joined points are calculated cow data points at the minimum and maximum age ranges. $\boldsymbol{\Delta}=$ Jersey (oleate $=17.4-.48$ Age) $\bullet \bullet=$ Limousin (oleate $=20.8-.08$ Age). $\mathrm{R}^{2}=.09$. Standard error of the difference was 1.6 for intercepts and .03 for slopes.

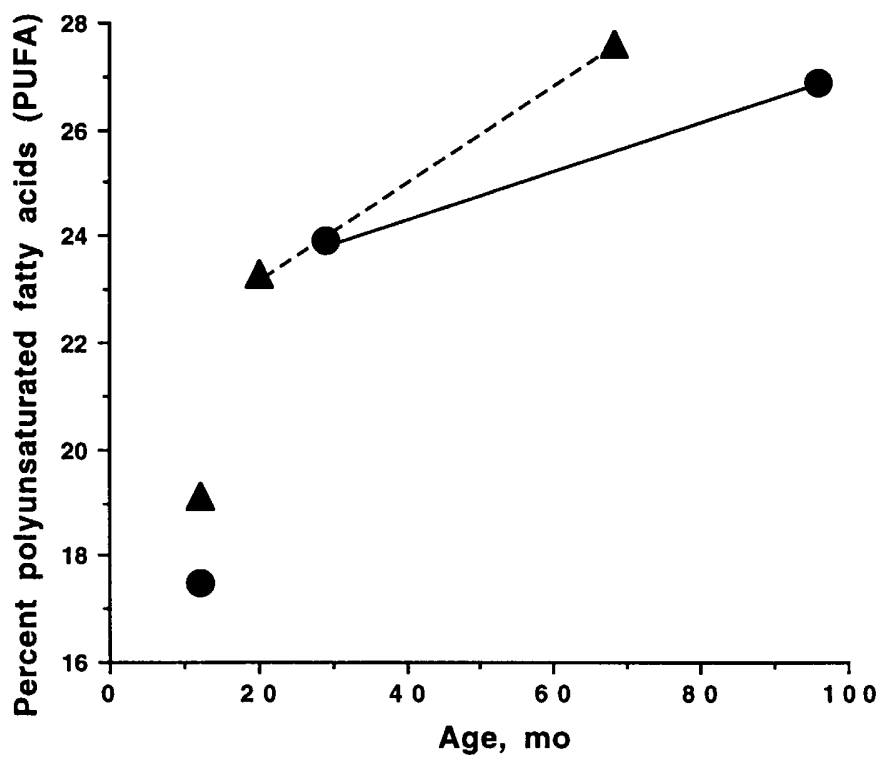

Figure 4. Relationship between muscle phospholipid PUFA and age. The unjoined data points represent yearling figures, and the joined points are calculated cow data points at the minimum and maximum age ranges. $\boldsymbol{\Delta}=$ Jersey $($ PUFA $=21.5+.09$ Age $) . \bullet=$ Limousin (PUFA $=24.8-.03$ Age) $. \mathrm{R}^{2}=.05$. Standard error of the difference was 2.2 for intercepts and .04 for slopes. 
Table 3. Least squares means $\pm \mathrm{SE}$ of muscle phospholipid composition ( $\%$ of total fatty acids)

\begin{tabular}{|c|c|c|c|c|}
\hline \multirow[b]{2}{*}{ Fatty acid } & \multicolumn{2}{|c|}{ Cows } & \multicolumn{2}{|c|}{ Yearlings } \\
\hline & J ersey & Limousin & J ersey & Limousin \\
\hline $14: 0$ & $.6 \pm .1$ & $.4 \pm .1$ & $.1 \pm .1^{*}$ & $.7 \pm .1$ \\
\hline 14:1 & $.7 \pm .3$ & $.5 \pm .3$ & $.6 \pm .3$ & $.7 \pm .3$ \\
\hline $16 \mathrm{DMA}^{\mathrm{a}}$ & $6.9 \pm .7$ & $7.8 \pm .9$ & $4.0 \pm .7 *$ & $5.1 \pm .7$ \\
\hline 16:0 & $15.5 \pm .5^{* *}$ & $17.8 \pm .6$ & $19.7 \pm 1.0$ & $20.3 \pm 1.0$ \\
\hline 16:1 & $2.1 \pm .2$ & $1.6 \pm .2$ & $2.2 \pm .2$ & $1.9 \pm .2$ \\
\hline $17: 0$ & $1.4 \pm .2^{*}$ & $.7 \pm .2$ & $.7 \pm .2$ & $.5 \pm .2$ \\
\hline 17:1 & $1.7 \pm .2$ & $1.8 \pm .3$ & $1.0 \pm .3$ & $1.2 \pm .3$ \\
\hline 18DMA & $5.4 \pm .5$ & $5.0 \pm .7$ & $3.3 \pm .8$ & $3.6 \pm .8$ \\
\hline 18:0 & $14.0 \pm .5$ & $13.7 \pm .6$ & $19.0 \pm .8^{*}$ & $16.2 \pm .8$ \\
\hline $18: 1(n-9)$ & $16.9 \pm .6$ & $18.3 \pm .7$ & $22.1 \pm 1.2$ & $24.2 \pm 1.2$ \\
\hline $18: 1(n-7)$ & $1.4 \pm .3^{*}$ & $2.3 \pm .4$ & $1.3 \pm .3$ & $1.1 \pm .3$ \\
\hline $18: 2$ & $8.4 \pm .4$ & $8.1 \pm .5$ & $7.7 \pm .9$ & $6.3 \pm .9$ \\
\hline $18: 3(n-3)$ & $2.1 \pm .2$ & $2.3 \pm .3$ & $1.3 \pm .4$ & $1.0 \pm .4$ \\
\hline $18: 3(n-6)$ & $1.6 \pm .3 * *$ & $.1 \pm .4$ & $.3 \pm .1$ & $.1 \pm .1$ \\
\hline $18: 4$ & $.6 \pm .2^{*}$ & $.1 \pm .2$ & $.4 \pm .2$ & $.1 \pm .2$ \\
\hline $20: 0$ & $2.5 \pm .4$ & $1.5 \pm .5$ & $.5 \pm .5$ & $.4 \pm .5$ \\
\hline $20: 1$ & $.3 \pm .2$ & $.3 \pm .2$ & $.3 \pm .1$ & $.1 \pm .1$ \\
\hline $20: 2$ & $.6 \pm .2$ & $.8 \pm .2$ & $.8 \pm .5$ & $.9 \pm .5$ \\
\hline $20: 3$ & $1.4 \pm .2 *$ & $2.0 \pm .3$ & $.7 \pm .5^{*}$ & $2.1 \pm .5$ \\
\hline $20: 4$ & $5.0 \pm .3 * *$ & $6.4 \pm .4$ & $3.5 \pm .9$ & $4.0 \pm .9$ \\
\hline $20: 5$ & $2.1 \pm .2 * *$ & $1.3 \pm .2$ & $2.4 \pm .4^{* *}$ & $1.2 \pm .4$ \\
\hline $22: 0$ & $1.9 \pm .3$ & $1.6 \pm .4$ & $.4 \pm .6$ & $.4 \pm .6$ \\
\hline $22: 1$ & $1.1 \pm .3$ & $1.7 \pm .4$ & $2.0 \pm .7 * *$ & $5.5 \pm .7$ \\
\hline $22: 5$ & $1.0 \pm .3$ & $1.0 \pm .3$ & $1.5 \pm .4$ & $1.0 \pm .4$ \\
\hline $24: 0$ & $1.5 \pm .3 * *$ & $.8 \pm .3$ & $.1 \pm .1$ & $.1 \pm .1$ \\
\hline $22: 6$ & $.2 \pm .2$ & $.2 \pm .2$ & $.5 \pm .3$ & $.3 \pm .3$ \\
\hline 24:1 & $3.1 \pm .4$ & $1.7 \pm .6$ & $3.6 \pm 1.1^{* *}$ & $.5 \pm 1.1$ \\
\hline SFA & $49.7 \pm 1.1$ & $49.3 \pm 1.4$ & $47.8 \pm 1.5$ & $47.3 \pm 1.5$ \\
\hline MUFAC & $27.3 \pm .9$ & $28.4 \pm 1.2$ & $33.1 \pm 1.8$ & $35.2 \pm 1.8$ \\
\hline PUFA $^{d}$ & $23.0 \pm 1.0$ & $22.3 \pm 1.2$ & $19.1 \pm 1.7$ & $17.5 \pm 1.7$ \\
\hline$(n-3) P \cup F A^{e}$ & $7.6 \pm .5$ & $6.3 \pm .7$ & $6.0 \pm .9 *$ & $3.6 \pm .9$ \\
\hline$(n-6) P \cup F A^{f}$ & $16.4 \pm .7$ & $16.6 \pm .9$ & $12.3 \pm 1.5$ & $12.5 \pm 1.5$ \\
\hline$\Delta^{9}$-desat $(16)^{\mathrm{g}}$ & $8.6 \pm .9 *$ & $5.9 \pm 1.1$ & $8.5 \pm 1.1$ & $7.0 \pm 1.1$ \\
\hline$\Delta^{9}$-desat $(18)^{\mathrm{h}}$ & $54.7 \pm .7$ & $57.2 \pm .8$ & $53.8 \pm 1.3^{* *}$ & $59.9 \pm 1.3$ \\
\hline Elongase ${ }^{i}$ & $63.7 \pm .6^{*}$ & $62.3 \pm .7$ & $65.2 \pm 1.4$ & $64.5 \pm 1.4$ \\
\hline Ratio of unsaturated:saturated & $1.0 \pm .04$ & $1.0 \pm .04$ & $1.1 \pm .07$ & $1.1 \pm .07$ \\
\hline Ratio of polyunsaturated:saturated & $.5 \pm .03$ & $.5 \pm .03$ & $.4 \pm .05$ & $.4 \pm .04$ \\
\hline
\end{tabular}

Ratio of polyunsaturated:saturated

aDMA = di-methyl-acetals (Sinclair and O'Dea, 1987)

bSFA = saturated fatty acids.

CMUFA = monounsaturated fatty acids.

dPUFA = polyunsaturated fatty acids.

e $(n-3) P U F A=18: 3(n-3)+18: 4+20: 5+22: 5+22: 6$.

$f(n-6) P U F A=18: 2+18: 3(n-6)+20: 3+20: 4$

${ }^{9}{ }^{9}$-desat(16): index of desaturase enzyme activity in C16 fatty acids $=100(16: 1 / 16: 0+16: 1)$.

$\mathrm{h}_{\Delta}{ }^{9}$-desat(18): index of desaturase enzyme activity in C18 fatty acids $=100[(18: 1(\mathrm{n}-9) / 18: 0+18$ : $1(n-9))]$.

'Elongase: Index of el ongase enzyme activity in the chain lengthening of C16-C18 fatty acids $=100[(18$ :

$0+18: 1(n-9)) /(16: 0+16: 1+18: 0+18: 1(n-9))]$.

$* \mathrm{P}<.05$.

$* * \mathrm{P}<.01$

equations were low, which indicates that the regression equations would be poor predictors of fatty acid percentages.

The effect of age was different in the two breeds, as indicated by significant breed $\times$ age interactions in the percentages of 20:3, 22:5 (clupadonate), and total PUFA (Table 2). All the other major fatty acids were unaffected by this interaction. In general, as animals aged, the proportions of 18DMA (di-methyl acetals), 18:2 (linoleate), 18:3(n-3), 20:0, 20:4, and total
PUFA increased (Table 3). In contrast, 16:0, 18:0, 18: 1 (n-9), 22:1, total SFA, and MUFA decreased with increasing age.

Yearling Data. Sex and breed differences were significant among yearlings (Table 2). Steers had more 14:0 (myristate), 16:1 (palmitoleate), 18:0, 18: 1(n-9), 18:1(n-7), 22:1 (erucate), and total MUFA than heifers. Heifers had more 16DMA, 18DMA, 18:2 (linoleate), 20:4, 20:5, total PUFA, (n-3) PUFA, and $(n-6)$ PUFA and a higher ratio of PUFA to SFA than 
steers (Table 3 ). Limousin yearlings had more 14:0, 16DMA, 20:3, and 22:1, and a greater $\Delta^{9}$-desaturase (C18) enzyme index, and less 18:0, 20:5, and 24:1 than their J ersey counterparts (Table 3).

The sex $\times$ breed interaction was not a significant source of variation for most of the fatty acids except 14:0, 16:0, 22:1, and total SFA (Table 2). Limousin heifers had more $16: 0$ ( 21.7 vs $16.9 \%$ ), and steers had less (18.8 vs $22.5 \%$ ) than their J ersey counterparts. There were no clearly defined patterns in the levels of 14:0 and 22:1. In contrast, Limousin heifers and steers had more ( 51.9 vs $47.1 \%$ ) and less ( 42.7 vs $48.5 \%)$ SFA than Jersey heifers and steers, respectively.

The most abundant saturated fatty acids in muscle phospholipids are 16:0 and 18:0 (Table 3). A general observation of the cow and yearling data indicated that yearlings had more 16:0 and 18:0 than the cows (19.7 and $15.5 \%$ for Limousin and 20.3 and $17.8 \%$ for J ersey, respectively). Also, 18:1(n-9), 22:1, and total MUFA were higher in the yearlings than in the cows. Yearlings had less 18:2, 18:3(n-3), 20:4, and total PUFA than cows (Table 3).

\section{Discussion}

Selection of cattle for desirable traits can only be effective if the breeds differ. To be able to make unbiased comparisons, it is essential that the breeds be treated similarly in terms of nutritional regimen, management, and environment. Unfortunately, most bovine fatty acid composition data in the literature originate from breeds on diverse diets (HuertaLeidenz et al., 1991), ages (Clemens et al., 1973), sexes (Zembayashi et al., 1995), and anatomical sites (Westerling and Hedrick, 1979). This makes it difficult to extrapolate the results and compare breeds universally because of the confounding effects of plane of nutrition, age, fatness, live weight, developmental traits, and other factors that affect lipid metabolism (Huerta-Leidenz et al., 1996). In our study, all the animals were purebreds, fed on pasture only, under the same management conditions, and the muscle samples were taken from the same anatomical site. Having eliminated most of these obvious phenotypic sources of variation, the breeds were compared for differences in fatty acid composition of the phospholipid fraction of the muscle.

Breed Differences. The notable breed differences in phospholipid composition between J erseys and Limousins complement our previous comparison of their triacylglycerol fractions from the adipose tissue (Malau-Aduli et al., 1997). Limousin cows had more palmitate (17.8\%) than J ersey cows (15.5\%) in their muscle phospholipid fractions (present study) compared with 30.2 and $28.2 \%$ in their adipose tissues (Malau-Aduli et al., 1997), respectively. Regardless of the tissue, it is clear that the two breeds differ in palmitate content; the magnitude of the difference was even greater in phospholipids. In purebred J apanese Black and Holstein cattle, significant breed differences of 12.4 and $14.0 \%$, respectively, in phospholipid palmitate were reported (Zembayashi et al., 1995). In the present study, a breed difference of $2.6 \%$ was obtained between J ersey and Limousin cows.

The other individual fatty acids, vaccenate [18: $1(n-7)]$, margerate (17:0), gamma-linolenate [18: $3(n-6)]$, octadecatetraenoate (18:4), di-homogammalinolenate (20:3), eicosapentanoate (20:5), and lignocerate $(24: 0)$ varied between breeds, but the proportions were small in absolute terms. Arachidonate (20:4) is a metabolite of linoleate (18: 2 ), which has a dietary origin because it cannot be synthesized by the mammals. Limousin cows had more arachidonate than J ersey cows. This difference in 20:4 is unlikely to be dietary, because there was no difference in 18:2. This suggests a genetic difference due to lesser $\Delta 5$ desaturase activity (responsible for the conversion of 20:3 to 20:4) or lower elongase activity as a result of the relative accumulation of 18 : $3(n-6)$ in the Jersey breed. Other researchers (Tanaka, 1985; Eichorn et al., 1986; Siebert et al., 1996) have also reported such differences in other breeds of cattle raised in feedlots.

Breed differences were not only limited to the cows. The yearling data also revealed significant breed differences. However, such differences were detected in fewer fatty acids compared to the cow data. We had demonstrated previously (Malau-Aduli et al., 1997) that there were no breed differences detected in most of the triacylglycerol fatty acids in J ersey and Limousin yearlings. A similar trend seems to be the case in muscle phospholipids. This is supported by a report (Zembayashi et al., 1995) in which only iso-16: 0 and 16:0 fatty acids in the intramuscular phospholipids of J apanese Black, Holsteins, and their $F_{1}$ crossbred steers were found to be significantly different. In the present study, Limousin yearlings had significantly different percentages of myristate (14:0), 16-dimethyl-acetals (16DMA), stearate (18:0), 20:3, 20:5, and 24:1 from Jersey yearlings.

Of interest, too, are the calculated indices $\Delta^{9}$ desaturase and elongase activities. Myristate, palmitate, and stearate are converted to their (n-9) corresponding monounsaturated fatty acids by $\Delta^{9}$ desaturase (Zembayashi et al., 1995), and palmitate is converted to stearate through chain elongation by el ongase (Huerta-Leidenz et al., 1996). The activities of elongase and $\Delta^{9}$-desaturase have been detected in bovine subcutaneous adipose tissue (St. John et al.,1991; Chang et al., 1992), and mathematical indices for calculating the activities of the two enzymes were postulated (Malau-Aduli et al., 1997). Our data in this study showed that J ersey cows had greater indices of $\Delta^{9}$-desaturase in $\mathrm{C} 16$ fatty acids and elongase than Limousin cows, and J ersey yearlings 
Table 4. Least squares means $\pm \mathrm{SE}$ of muscle phospholipids by sex $(\%)$

\begin{tabular}{lccc}
\hline \hline Fatty acid & Heifers & Steers & Significance \\
\hline $14: 0$ & $.1 \pm .1$ & $.7 \pm .1$ & $* *$ \\
$16 D M A^{b}$ & $7.3 \pm .5$ & $1.8 \pm .8$ & $* *$ \\
$16: 1$ & $1.6 \pm .2$ & $2.5 \pm .3$ & $*$ \\
$18 D M A$ & $5.7 \pm .6$ & $1.3 \pm .7$ & $* *$ \\
$18: 0$ & $14.8 \pm .6$ & $20.4 \pm .9$ & $* *$ \\
$18: 1(n-9)$ & $19.8 \pm .9$ & $26.5 \pm 1.5$ & $* *$ \\
$18: 1(n-7)$ & $.4 \pm .2$ & $2.0 \pm .4$ & $* *$ \\
$18: 2$ & $9.8 \pm .7$ & $4.2 \pm 1.1$ & $* *$ \\
$20: 4$ & $5.8 \pm .6$ & $1.7 \pm 1.1$ & $* *$ \\
$20: 5$ & $3.1 \pm .3$ & $.5 \pm .5$ & $* *$ \\
$22: 1$ & $.2 \pm .1$ & $7.2 \pm .8$ & $* *$ \\
MUFA & $25.1 \pm 1.3$ & $42.8 \pm 2.2$ & $* *$ \\
PUFA & $26.4 \pm 1.2$ & $11.6 \pm 2.1$ & $* *$ \\
(n-3)PUFA & $8.2 \pm .6$ & $3.3 \pm .1$ & $* *$ \\
(n-6)PUFA & $17.4 \pm 1.8$ & $7.3 \pm 1.0$ & $* *$ \\
Ratio of polyunsaturated: & & & \\
saturated & $.54 \pm .03$ & $.27 \pm .06$ & $* *$ \\
Elongase & $62.5 \pm 1.0$ & $66.8 \pm 1.6$ & $*$ \\
\hline
\end{tabular}

${ }^{a}$ Only fatty acids that significantly differed are shown.

bDMA = di-methyl-acetals (Sinclair and O'Dea, 1987).

$* P<.05$.

$* * \mathrm{P}<.01$.

had less $\Delta^{9}$-desaturase index in C18 fatty acids than did Limousin yearlings. After a similar observation (Sturdivant et al., 1992), it was postulated that elevated stearoyl-CoA desaturase enzyme activity could be responsible for the elevated percentage of 18: 1 (n-9) in Wagyu cattle adipose tissue.

Sex Differences. Differences in phospholipid fatty acids between steers and heifers were observed. Specifically, steers had more 14:0, 16:1, 18:0, 18: $1(n-9), 18: 1(n-7), 22: 1$, and MUFA, less 18:2, 20:4, 20:5, total PUFA, (n-3) PUFA, and (n-6) PUFA, and a lower ratio of PUFA to SFA than heifers (Table 4). We postulate that hormonal differences between steers and heifers resulted in most of the sex differences observed in our study. It has been reported (Prior et al., 1983) that the manipulation of sex hormone status of living cattle influenced lipid metabolism in the adipose tissue and that sex differences are known to be associated with hormonal changes and their possible influence on enzymatic systems. Our study seems to indicate that this is not limited to the adipose tissue, but applies to the muscle tissue as well. However, cellular mechanisms for this relationship are not fully understood, especially in ruminants (Vernon, 1986).

Reports of sex differences in fatty acid composition in the literature are not consistent. For instance, studies with pigs (Allen et al., 1967) and cattle (Terrel et al., 1968) showed that sex effects were associated with the neutral fraction rather than the phospholipid fraction fatty acids. In contrast, reports that percentages of 14:0,14:1, 16:1, and 20:5 of intramuscular phospholipids are higher in heifers than in steers have been published (Hornstein et al., 1961; Larick et al., 1989; Zembayashi et al., 1995). Similarly, heifers had higher percentages of 18: $1(n-9)$ and lower percentages of 14:0, 16:0, and 18:0 than steers (Waldman et al., 1968; Terrel et al., 1969; Marchello et al., 1970).

Age Differences. In cattle, an association between fatty acid composition and age exists. Our data showed that percentages of phospholipid 16:0, 18:0, and 18:1(n-9) decreased with age, and total polyunsaturated fatty acids increased. We had reported a decrease in the total saturated fatty acid content and a concomitant increase in the percentage of total monounsaturated fatty acids in the adipose tissue in Limousin and Jersey cattle with increasing age (Malau-Aduli et al., 1997).

The decrease in palmitate and stearate with age suggests that these saturated fatty acids were progressively diluted with fatty acids of higher unsaturation. Unlike the adipose tissue, in which MUFA increased with age, (Malau-Aduli et al., 1997), the present data showed that this increase in unsaturation was observed in PUFA, which abound in high proportions in the muscle tissue. This indirectly suggests that the desaturase enzymes, which convert saturated to unsaturated fatty acids, selectively favor the introduction of more than one double bond in the fatty acid chain. Thus, the possibility of $\Delta^{5}$ and $\Delta^{6}$ desaturase becoming more active than $\Delta^{9}$ desaturase in the conversion of saturated to unsaturated fatty acids seems likely. Other researchers have demonstrated that 12:0, 14:0, and 18:0 decreased with growth and age in Angus, Hereford, and Brahman cattle (Hecker et al., 1975; Huerta-Leidenz et al., 1996).

\section{Implications}

This study indicates clearly that breed, sex, and age are important sources of variation in muscle phospholipids. Because the cattle used in this study were under the same management conditions, our results suggest a genetic basis for the differences in the fatty acid composition of muscle phospholipids in Limousin and J ersey cattle.

\section{Literature Cited}

Allen, E.R.W., R. W. Bray, and R. G. Cassens. 1967. Changes in fatty acid composition of porcine muscle lipid associated with sex and weight. J. Food Sci. 32:26-30.

Chang, J.H.P., D. K. Lunt, and S. B. Smith. 1992. Fatty acid composition and fatty acid elongase and stearoyl-CoA desaturase activities in tissues of steers fed high oleate sunflower seed. J. Nutr. 122:2074-2079.

Christie, W. W. 1989. Gas Chromatography and Lipids. The Oily Press, Oxford, U.K.

Clemens, E., V. Arthaud, R. Mandigo, and W. Woods. 1973. Fatty acid composition of bulls and steers as influenced by age and dietary energy level. J. Anim. Sci. 37:1326-1331. 
Eichhorn, J . M., L. J . Coleman, E. J . Wakayama, G. J . Blomquist, C. M. Bailey, and T. G. J enkins. 1986. Effects of breed type and restricted versus ad libitum feeding on fatty acid composition and cholesterol content of muscle and adipose tissue from mature bovine females. J. Anim. Sci. 63:781-794.

Hecker, A. L., D. A. Cramer, and D. F. Hougham. 1975. Compositional and metabolic growth effects in the bovine muscle, subcutaneous and serum total fatty acids. J . Food Sci. 40:144-149.

Hornstein, P. E., P. F. Crowe, and M. J . Heimberg. 1961. Fatty acid composition of meat tissue lipids. J. Food Sci. 26:581-588.

Huerta-Leidenz, N. O., H. R. Cross, D. K. Lunt, L. S. Pelton, J . W. Savell, and S. B. Smith. 1991. Growth, carcass traits, and fatty acid profiles of adipose tissues from steers fed whole cottonseed. J. Anim. Sci. 69:3665-3672.

Huerta-Leidenz, N. O., H. R. Cross, J. W. Savell, D. K. Lunt, J. F. Baker, L. S. Pelton, and S. M. Smith. 1993. Comparison of the fatty acid composition of subcutaneous adipose tissue from mature Brahman and Hereford cows. J . Anim. Sci. 71:625-630.

Huerta-Leidenz, N. O., H. R. Cross, J. W. Savell, D. K. Lunt, J . F. Baker, and S. B. Smith. 1996. Fatty acid composition of subcutaneous adipose tissue from male calves at different stages of growth. J. Anim. Sci. 74:1256-1264.

Larick, D. K., B. E. Turner, R. M. Koch, and J. D. Crouse. 1989. Influence of phospholipid content and fatty acid composition of individual phospholipids in muscle from Bison, Hereford and Brahman steers on flavour. J. Food Sci. 54:521-527.

Malau-Aduli, A.E.O., B. D. Siebert, C.D.K. Bottema, and W. S. Pitchford. 1997. A comparison of the fatty acid composition of triacylglycerols in adipose tissue from Limousin and J ersey cattle. Aust. J. Agric. Res. 48:715-722.

Marchello, J. A., M. Vavra, F. D. Dryden, and D. E. Ray. 1970. Influence of sex on certain constituents of bovine muscles. J . Anim. Sci. 31:707-712.

Prior, R. L., S. B. Smith, R. D. Schanbacher, and H. J . Mersmann. 1983. Lipid metabolism in finishing bulls and steers implanted with oestradiol-17 $\beta-\alpha$ :propionate. Anim. Prod. 37:81-85.

SAS. 1989. SAS U sers Guide: Statistics (Version 6). SAS Inst., Inc., Cary, NC.

Scott, T. W., and J. R. Ashes. 1993. Dietary lipids for ruminants: Protection, utilization and effects on remodelling of skeletal muscle lipids. Aust. J. Agric. Res. 44:495-508.

Siebert, B. D., M.P.B. Deland, and W. S. Pitchford. 1996. Breed differences in the fatty acid composition of subcutaneous and intramuscular lipid of early and late maturing, grain-finished cattle. Aust. J. Agric. Res. 47:943-952.
Simopoulos, A. M. 1994. Fatty acid composition of skeletal muscle, membrane phospholipids, insulin resistance and obesity. Nutr. Today (J an/F eb):12-16.

Sinclair, A. J., and K. O'Dea. 1987. The lipid levels and fatty acid compositions of the lean portions of Australian beef and lamb. Food Technol. Aust. 39:228-231.

St. J ohn, L. C., D. K. Lunt, and S. B. Smith. 1991. Fatty acid elongation and desaturation enzyme activities of bovine liver and subcutaneous adipose tissue microsomes. J . Anim. Sci. 69: 1064-1073.

Sturdivant, C. A., D. K. Lunt, G. C. Smith, and S. B. Smith. 1992. Fatty acid composition of subcutaneous and intramuscular adipose tissues and $\mathrm{M}$. Iongissimus dorsi of Wagyu cattle. Meat Sci. 32:449-452.

Tanaka, S. 1985. Chemical studies on the adipose tissues and muscle lipids of fattening beef cattle III. Neutral and phospholipid deposition and fatty acid composition as related to breeds and muscles. J pn. J. Dairy Food Sci. 34:A61.

Terrell, R. N., G. G. Suess, and R. W. Bray. 1969. Influence of sex, liveweight and anatomical location on bovine lipids. I. Fatty acid composition of subcutaneous and intermuscular fat depots. J. Anim. Sci. 28:449-452.

Terrell, R. N., G. C. Suess, R. G. Cassens, and R. W. Bray. 1968. Broiling, sex and interrelationships with carcass and growth characteristics and their effect on the neutral and phospholipid fatty acids of the bovine longissimus dorsi. J. Food Sci.33: 562-567.

Van Oeckel, M. J ., M. Casteels, N. Warnants, L. Van Damme, and C. V. Boucque. 1996. Omega-3 fatty acids in pig nutrition: Implications for the intrinsic and sensory quality of the meat. Meat Sci. 44:55-63.

Vernon, R. G. 1986. The growth and metabolism of adipocytes. In: J . Buttery, N. B. Haynes, and D. B. Lindsay (Ed.) Control and Manipulation of Animal Growth. p 67. Butterworths, London.

Waldman, R. C., G. G. Suess, and V. H. Brungardt. 1968. Fatty acids of certain bovine tissue and their association with growth, carcass and palatability traits. J. Anim. Sci. 27:632-635.

Westerling, D. B., and H. B. Hedrick. 1979. Fatty acid composition of bovine lipids as influenced by diet, sex and anatomical location and relationship to sensory characteristics. J. Anim. Sci. 48: 1343-1348.

Zembayashi, M., K. Nishimura, D. K. Lunt, and S. B. Smith. 1995. Effect of breed type and sex on the fatty acid composition of subcutaneous and intramuscular lipids of finishing steers and heifers. J. Anim. Sci. 73:3325-3332. 